\title{
Age and growth of the undulate ray, Raja undulata, in the Algarve (Southern Portugal)
}

\author{
Rui Coelho* and Karim Erzini \\ Universidade do Algarve, CGMAR/FCMA, Campus de Gambelas, 8000-117 Faro, Portugal. \\ *Corresponding author, e-mail: rpcoelho@ualg.pt
}

\begin{abstract}
Aspects of the population dynamics of the undulate ray, Raja undulata (Chondrichthyes: Rajidae), one of the more abundant elasmobranch fishes captured along the Portuguese south coast (Algarve), were studied for the first time. Some traditional elasmobranch vertebral enhancing techniques were compared and the most precise for this species determined to be the cedar wood oil immersion and the alizarin red $\mathrm{S}$ stain. The sample consisted of 14 age classes, with age classes 3 to 8 being the most represented. Evidence of an annual deposition pattern of a pair of bands (one opaque and one translucent) was found by marginal increment analyses. Von Bertalanffy growth parameters were estimated and no differences found between males and females (all data: $\mathrm{L}_{\text {inf }}=110.22 \mathrm{~cm}, \mathrm{~K}=0.11$ year ${ }^{-1}$ and $\mathrm{t}_{0}=-1.58$ year).
\end{abstract}

\section{INTRODUCTION}

Due to their characteristic slow growth rates, low fecundity with delayed reproductive effort, geared towards the production of a small progeny after a long gestation period, elasmobranch fishes are highly susceptible to overexploitation (Stevens et al., 2000). In recent years, these fishes have become important fisheries resources, with increasing fishing effort. In Portugal, particularly in the Algarve, catches of rays decreased more than $42 \%$ in the last ten years, while their commercial value has increased more than $71 \%$ (DGPA, 2000).

Several methods have been successfully used for aging elasmobranchs, namely length-frequency analysis, tagging studies and interpretation of growth bands deposited on the available calcified vertebrae. Cailliet (1983) presented a revision of several of these techniques.

The objectives of this study were the assessment of the most precise techniques for aging Raja undulata Lacepède, 1802 followed by the estimation of age and growth parameters. These parameters are essential for the assessment and evaluation of the state of the stock in Algarve waters.

\section{MATERIAL AND METHODS}

Sampling took place between October 1999 and February 2001 by fishing vessels operating along the Algarve coast. Captured fish were brought to the laboratory and information on sex, total length (TL, cm), disk width (DW, $\mathrm{cm}$ ) and total weight (TW, g) recorded for each specimen. Vertebrae were removed from the anterior zone of the vertebral column (DuBuit, 1972) and cleaned according to the methodology proposed by Cailliet et al. (1983).

Preliminary tests with silver nitrate (Stevens, 1975), cobalt nitrate (Hoenig \& Brown, 1988), histological procedure of dehydration followed by paraffin impregnation (Daiber, 1960), cedar wood oil immersion (Cailliet et al., 1983), nitric acid decalcification (Correia \& Figueiredo, 1997) and alizarin red S dye (LaMarca, 1966) were conducted in a sub-sample of 30 specimens (22.4 to $81.2 \mathrm{~cm} \mathrm{TL})$. These different techniques were applied to whole vertebrae, halves and $300 \mu \mathrm{m}$ longitudinal sections (Waring, 1984). To evaluate the efficiency of each technique, three independent readings temporally spaced by a minimum of 30 days were made by a single reader, and several precision indices calculated, namely the per cent concordance, the index of average percent error proposed by Beamish \& Fournier (1981) and the coefficient of variation and precision index, both proposed by Chang (1982).

Based on the results of these preliminary tests, the technique of cedar wood oil immersion of whole vertebrae was applied to the remaining sample. For the larger specimens, where band observation and counting was more difficult, the technique of the alizarin red $\mathrm{S}$ stain was applied to $300 \mu \mathrm{m}$ longitudinal sections. Each vertebra was observed by one reader on three separate occasions, temporally spaced by a minimum of 30 days. A valid age was only considered if the same age was attributed at least twice. Mean lengths-at-age between sexes were compared by Student's $t$-tests. Age was validated by marginal increment analysis. To evaluate the pattern of band deposition along the year, the vertebrae edge of a minimum of ten specimens per month was classified as either opaque or translucent.

The von Bertalanffy growth function was fitted to the length-at-age data, and the parameters estimated by the non-linear least squares method. Ages were attributed assuming a birth date of 1 January, which allowed the variability associated with having a large sampling period to be minimized. Male and female growth parameters were compared with the maximum likelihood test.

\section{RESULTS}

The sample consisted of 187 specimens, with 94 (50.3\%) males and $93(49.7 \%)$ females. Lengths ranged from 19.4 to $88.2 \mathrm{cmTL}$. Fourteen individuals were caught with beach 
Table 1. Precision of the tested techniques applied to the different treatments on vertebrae of Raja undulata. The $\%$ concordance represents the cumulative percentage of concordant readings in a determinate number of years $(0, \pm 1$, \pm 2 and \pm 3$)$. The calculated precision indexes are the average percent error (APE), the coefficient of variation $(V)$ and the precision index $(D)$. The percentage of readings that did not allow the estimation of a valid age $(\mathcal{N D})$ is also given.

\begin{tabular}{|c|c|c|c|c|c|c|c|c|c|}
\hline \multirow[b]{2}{*}{ Technique } & \multirow[b]{2}{*}{ Treatment } & \multicolumn{4}{|c|}{$\%$ concordance (years) } & \multicolumn{3}{|c|}{ Precision indexes } & \multirow{2}{*}{$\begin{array}{l}\text { ND } \\
(\%)\end{array}$} \\
\hline & & 0 & \pm 1 & \pm 2 & \pm 3 & APE & $\mathrm{V}$ & $\mathrm{D}$ & \\
\hline \multirow{3}{*}{$\begin{array}{l}\text { Alizarin red } \\
\text { S dye }\end{array}$} & Whole & 54.9 & 94.4 & 98.6 & 100.0 & 7.3 & 10.7 & 6.2 & 13.3 \\
\hline & Gut in half & 55.6 & 93.8 & 100.0 & - & 6.2 & 8.4 & 4.8 & 6.7 \\
\hline & Sectioned & 58.9 & 92.0 & 100.0 & - & 4.0 & 5.4 & 3.1 & 0.0 \\
\hline \multirow{3}{*}{$\begin{array}{l}\text { Cedar wood oil } \\
\text { immersion }\end{array}$} & Whole & 51.8 & 83.5 & 98.8 & 100.0 & 8.6 & 9.5 & 5.5 & 4.4 \\
\hline & Gut in half & - & - & - & - & - & - & - & 100.0 \\
\hline & Sectioned & - & - & - & - & - & - & - & 100.0 \\
\hline \multirow[t]{3}{*}{ Colbalt nitrate } & Whole & 54.9 & 94.4 & 98.6 & 100.0 & 9.2 & 12.5 & 7.2 & 13.3 \\
\hline & Cut in half & 46.8 & 91.1 & 100.0 & - & 8.0 & 10.9 & 6.3 & 7.8 \\
\hline & Sectioned & 42.7 & 91.5 & 98.8 & 100.0 & 4.8 & 6.6 & 3.8 & 6.7 \\
\hline \multirow{3}{*}{$\begin{array}{l}\text { Nitric acid } \\
\text { decalcification }\end{array}$} & Whole & - & - & - & - & - & - & - & 100.0 \\
\hline & Cut in half & - & - & - & - & - & - & - & 100.0 \\
\hline & Sectioned & - & - & - & - & - & - & - & 100.0 \\
\hline \multirow{3}{*}{$\begin{array}{l}\text { Paraffin } \\
\text { impregnation }\end{array}$} & Whole & 59.7 & 91.7 & 98.7 & 100.0 & 7.9 & 10.6 & 6.1 & 15.6 \\
\hline & Gut in half & - & - & - & - & - & - & - & 100.0 \\
\hline & Sectioned & 51.9 & 90.9 & 100.0 & - & 6.0 & 7.6 & 4.4 & 12.2 \\
\hline \multirow[t]{3}{*}{ Silver nitrate } & Whole & - & - & - & - & - & - & - & 100.0 \\
\hline & Cut in half & - & - & - & - & - & - & - & 100.0 \\
\hline & Sectioned & - & - & - & - & - & - & - & 100.0 \\
\hline
\end{tabular}

seines, 97 with trammel nets and the remaining 76 acquired in local fish markets.

The relation between TL and DW was linear with significant differences between males and females $\left(t-\right.$ stat $_{\mathrm{b}}$ : $P<0.001)$ :

All data: $\mathrm{TL}=1.61 \mathrm{DW}-3.03\left(r^{2}=0.98, \mathrm{~N}=182\right.$, range: 19.4 to $88.2 \mathrm{~cm} \mathrm{TL})$

Males: $\mathrm{TL}=1.66 \mathrm{DW}-4.45 \quad\left(r^{2}=0.98, \mathrm{~N}=93\right.$, range: 23.0 to $83.2 \mathrm{~cm} \mathrm{TL}$ )

Females: $\mathrm{TL}=1.58 \mathrm{DW}-2.27\left(r^{2}=0.99, \mathrm{~N}=89\right.$, range: 19.4 to $88.2 \mathrm{~cm} \mathrm{TL})$

The relation between the logarithm of TW and the logarithm of TL was linear with no significant difference between males and females $\left(t\right.$ stat $_{\mathrm{b}}: P=0.55$ and $t$-stat $\mathrm{a}_{\mathrm{a}}$ : $P=0.64)$ :

All data: $\log \mathrm{TW}=3.29 \log \mathrm{TL}-6.23\left(r^{2}=0.99, \mathrm{~N}=183\right.$, range: 19.4 to $88.2 \mathrm{~cm} \mathrm{TL}$ )

The most effective techniques for age estimation were staining both halved and sectioned vertebrae with alizarin red $\mathrm{S}$ and immersing whole vertebrae in cedar wood oil (Table 1). The latter technique has the advantage of being much less time consuming.

Age could not be estimated in only five specimens $(2.7 \%)$, because no clear visible patterns allowed two concordant readings, even after band enhancing techniques were applied. The sample consisted of 14 age-classes (ages 0 to 13 ), with the most representative age-classes between three and eight $(76.4 \%)$. Some overlapping of the lengthsat-age distributions was apparent, becoming greater for older age-classes. It was possible to observe that growth was more accelerated in the first years of life, and this was reflected by the progressive decrease of length increments with increasing age. Mean lengths-at-age of males and females showed differences for age classes one and eight ( $t$-test: $P<0.05$ in both cases), and no differences for the other age classes $(t$-test: $P>0.05)$.

To determine the periodicity of the band deposition pattern, 139 specimens $(74.3 \%$ of the total sample) were studied. It was possible to determine that a pair of bands (one opaque and one translucent) is deposited annually, with the opaque band deposited mostly during the summer (April to October) and the translucent band during the winter (December to March).

The length-at-age data and the fitted von Bertalanffy model are presented in Figure 1. The estimated parameters, with the respective standard errors in brackets, were:

All data: $\mathrm{L}_{\text {inf }}=110.22 \mathrm{~cm}(6.31), \mathrm{K}=0.11$ year $^{-1}(0.01)$ and $\mathrm{t}_{0}=-1.58$ year $(0.27) \quad\left(r^{2}=0.99, \mathrm{~N}=182\right.$, range: 19.4 to $88.2 \mathrm{~cm} \mathrm{TL}$ )

Males: $\mathrm{L}_{\text {inf }}=112.26 \mathrm{~cm}(11.99), \mathrm{K}=0.10$ year $^{-1}(0.02)$ and $\mathrm{t}_{0}=-1.23$ year $(0.48)\left(r^{2}=0.99, \mathrm{~N}=91\right.$, range: 23.0 to $83.2 \mathrm{~cm} \mathrm{TL}$ )

Females: $\mathrm{L}_{\text {inf }}=108.81 \mathrm{~cm}(7.24), \mathrm{K}=0.11$ year $^{-1}(0.02)$ and $\mathrm{t}_{0}=-1.55$ year $(0.34) \quad\left(r^{2}=0.99, \mathrm{~N}=91\right.$, range: 19.4 to $88.2 \mathrm{~cm} \mathrm{TL}$ )

No significant differences were found between males and females (maximum likelihood test: $P>0.05$ ). 


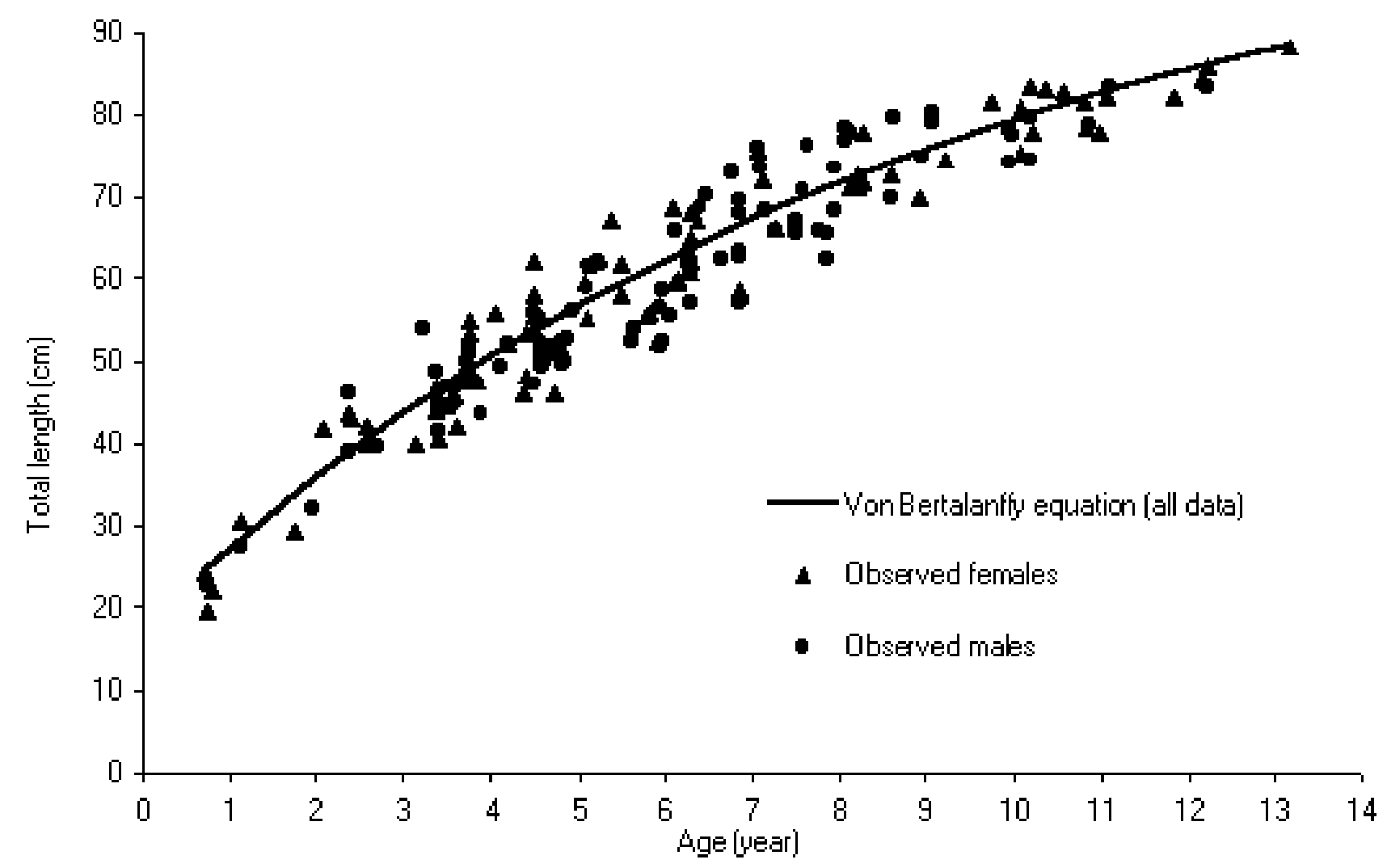

Figure 1. Growth of Raja undulata described by the von Bertalanffy growth function.

\section{DISCUSSION}

Following the advice of Beamish \& Fournier (1981), a preliminary test on the most effective band enhancing technique for the studied species was performed. We propose the use of an expeditious and effective technique, such as the cedar wood oil immersion, especially when a large sample needs to be analysed in a short time. For the more difficult structures, such as large vertebrae, a more elaborate and time consuming technique can be used, such as sectioning vertebrae in $300 \mu \mathrm{m}$ sections and staining with alizarin red $\mathrm{S}$. Both these techniques have been previously used with success for aging elasmobranchs (LaMarca, 1966; DuBuit, 1972; Cailliet et al., 1983).

The validation of age estimates is a critical aspect in age and growth studies. By the analysis of the band forming on the edge of the vertebrae, we concluded that a pair of bands, one opaque and one translucent, is formed each year, with the opaque band deposited mostly during the summer and the translucent band during the winter. This pattern had already been described in the Raja genus for $R$. clavata, $R$. microocellata, and $R$. montagui by Ryland \& Ajayi (1984) and for $R$. erinacea by Waring (1984).

Comparison of estimated growth parameters with those obtained by other authors for the Raja genus in European waters (DuBuit, 1972; Holden, 1972; Ryland \& Ajayi, 1984; Brander \& Palmer, 1985) showed that $R$. undulata has a relatively slow growth rate. The only species where lower growth rates have been described were $R$. batis (DuBuit, 1972) and R. clavata and R. microocellata (Ryland \& Ajayi, 1984).
This work was funded in part by the European Union (DG XIV Ref. 98/014) and by a grant from APECE, the Portuguese Association for the Study and Conservation of Elasmobranchs.

We would like to thank the following persons for their help throughout this work: Luis Bentes, Carla Correia, Pedro Lino, Pedro Monteiro, Joaquim Ribeiro and Jorge Gonçalves.

\section{REFERENCES}

Beamish, R.J. \& Fournier, D.A., 1981. A method for comparing the precision of a set of age determinations. Canadian Fournal of Fisheries and Aquatic Sciences, 38, 982-983.

Brander, K. \& Palmer, D., 1985. Growth rate of Raja clavata in Northeast Irish Sea. Fournal du Conseil International pour l'Exploration de la Mer, 42, 125-128.

Cailliet, G.M., Martin, L.K., Kusher, D., Wolf, P. \& Welden, B.A., 1983. Techniques for enhancing vertebral bands in age estimation of California elasmobranchs. In Proceedings of the international workshop on age determination of oceanic pelagic fishes: tunas, billfishes and sharks. (ed. E.D. Prince \& L.M. Pulos), pp. 29-33. US Department of Commerce. NOAA Technical Report NMFS 8.

Chang, W.Y., 1982. A statistical method for evaluating the reproducibility of age determination. Canadian Fournal of Fisheries and Aquatic Sciences, 39, 1208-1210.

Correia, J.P. \& Figueiredo, I.M., 1997. A modified decalcification technique for enhancing growth bands in deep-coned vertebrae of elasmobranches. Environmental Biology of Fishes, 50, 225-230.

Daiber, F.C., 1960. A technique for age determination in the skate, Raja eglanteria. Copeia, 3, 258-260.

DGPA, 2000. Recursos da pesca. Série Estatística 1999. DirecçãoGeral das Pescas e Aquicultura, vol. 13 A-B, 170 pp. 
DuBuit, M.H., 1972. Age et croissance de Raja batis et de Raja naevus en Mer Celtique. Fournal du Conseil International pour l'Exploration de la Mer, 37, 261-265.

Hoenig, J.M. \& Brown, C.A., 1988. A simple technique for staining growth bands in elasmobranch vertebrae. Bulletin of Marine Science, 42, 334-337.

Holden, M.J., 1972. The growth rates of Raja brachyura, R. clavata and $R$. montagui as determined from tagging data. Fournal $d u$ Conseil International pour l'Exploration de la Mer, 41, 111-120.

LaMarca, M.J., 1966. A simple technique for demonstrating calcified annuli in the vertebrae of large elasmobranches. Copeia, 2, 351-352.

Ryland, J.S. \& Ajayi, T.O., 1984. Growth and population dynamics of three Raja species (Batoidei) in Carmarthen Bay,
Brithish Isles. Fournal du Conseil International pour l'Exploration de la Mer, 41, 111-120.

Stevens, J.D., 1975. Vertebral rings as a means of age determination in the blue shark (Prionace glauca L). Fournal of the Marine Biological Association of the United Kingdom, 55, 657-665.

Stevens, J.D., Bonfil, R., Dulvy, N.K. \& Walker, P.A., 2000. The effects of fishing on sharks, rays, and chimaeras (chondrichthyans), and the implications for marine ecosystems. ICES Fournal of Marine Science, 57, 476-494.

Waring, G.T., 1984. Age, growth and mortality of the little skate off the northeast coast of the United States. Transactions of the American Fisheries Society, 113, 314-321.

Submitted 10 December 2001. Accepted 16 July 2002. 